Prepared for the U.S. Department of Energy

under Contract DE-AC05-76RL01830

\title{
DOE Solid-State Lighting in Higher Ed Facilities
}

The Nines Hotel, Portland, OR - May 25-27, 2010

NJ Miller
KJ Curry

July 2010

Pacific Northwest

NATIONAL LABORATORY

Proudly Operated by Battelle Since 1965 


\title{
DISCLAIMER
}

This report was prepared as an account of work sponsored by an agency of the United States Government. Neither the United States Government nor any agency thereof, nor Battelle Memorial Institute, nor any of their employees, makes any warranty, express or implied, or assumes any legal liability or responsibility for the accuracy, completeness, or usefulness of any information, apparatus, product, or process disclosed, or represents that its use would not infringe privately owned rights. Reference herein to any specific commercial product, process, or service by trade name, trademark, manufacturer, or otherwise does not necessarily constitute or imply its endorsement, recommendation, or favoring by the United States Government or any agency thereof, or Battelle Memorial Institute. The views and opinions of authors expressed herein do not necessarily state or reflect those of the United States Government or any agency thereof.

\author{
PACIFIC NORTHWEST NATIONAL LABORATORY \\ operated by \\ BATTELLE \\ for the \\ UNITED STATES DEPARTMENT OF ENERGY \\ under Contract DE-AC05-76RL01830
}

Printed in the United States of America

Available to DOE and DOE contractors from the

Office of Scientific and Technical Information,

P.O. Box 62, Oak Ridge, TN 37831-0062;

ph: (865) 576-8401

fax: (865) 576-5728

email: reports@adonis.osti.gov

\begin{abstract}
Available to the public from the National Technical Information Service, U.S. Department of Commerce, 5285 Port Royal Rd., Springfield, VA 22161 ph: (800) 553-6847 fax: $(703) 605-6900$ email: orders@ntis.fedworld.gov online ordering: http://www.ntis.gov/ordering.htm
\end{abstract}




\section{DOE Solid-State Lighting in Higher Ed Facilities}

The Nines Hotel, Portland, OR - May 25-27, 2010

NJ Miller

KJ Curry

July 2010

Prepared for

the U.S. Department of Energy

under Contract DE-AC05-76RL01830

Pacific Northwest National Laboratory

Richland, Washington 99352 



\section{Acknowledgments}

The SSL in Higher Education Workshop was a successful collaboration of many parties. The funding came from The American Recovery and Reinvestment Act of 2009, under the aegis of the Department of Energy. Ku'uipo Curry, intern at Pacific Northwest National Laboratory, provided the energy and organization for planning and executing the Workshop. Theresa Shoemaker of PNNL provided the experienced work in negotiations, arrangements, contracts, and protocols for the Workshop, conference space, and producing the final report. Of course, much of the outcome is also due to a wonderful slate of speakers, discussion leaders, and enthusiastic audience. 



\section{Contents}

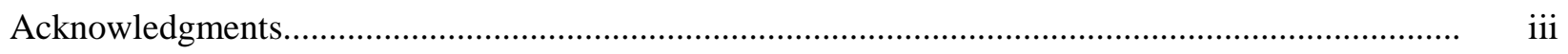

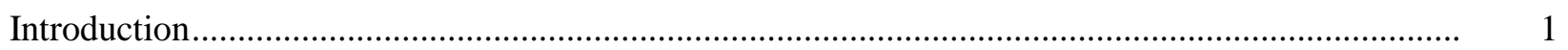

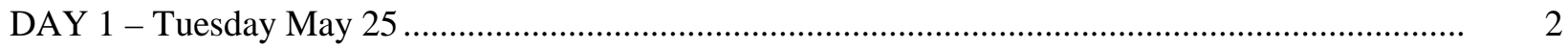

"Live Long and Prosper?” Where do LEDs make sense in the energy efficient lighting world?............................................................................................................... 2

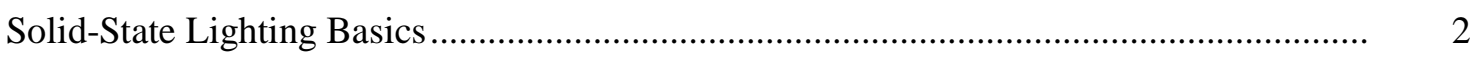

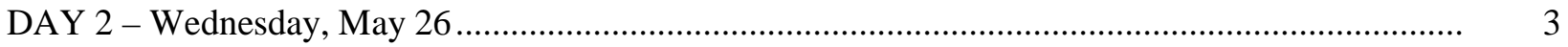

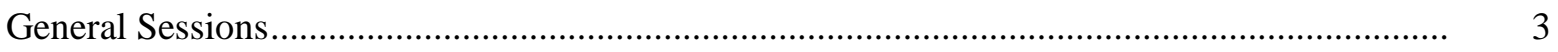

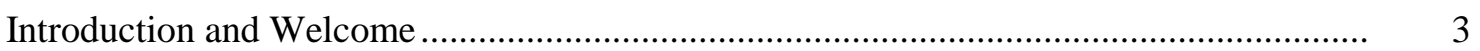

Lighting Design: the Barriers to LED Adoption ............................................................ 3

More than Watts and Footcandles: Designing, Building and Maintaining Attractive and Effective Spaces ........................................................................................... 3

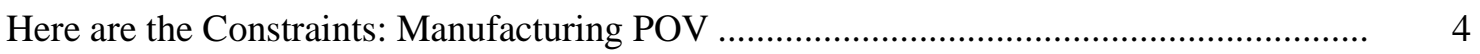

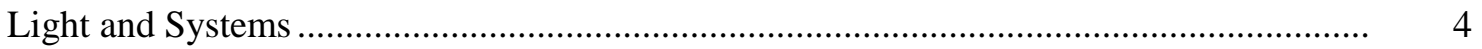

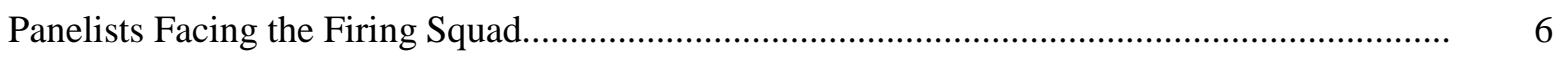

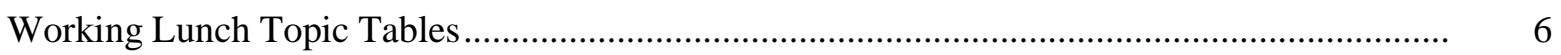

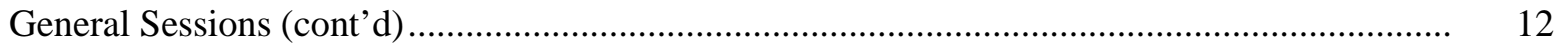

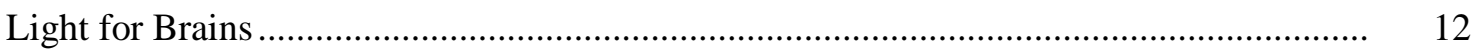

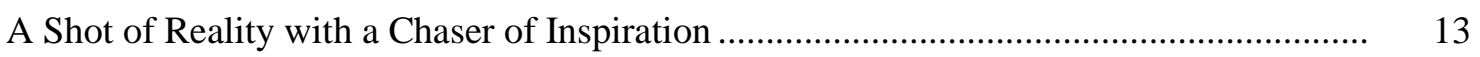

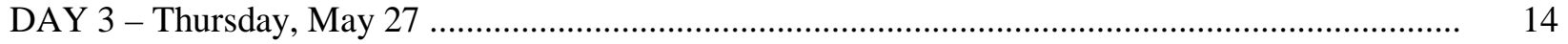

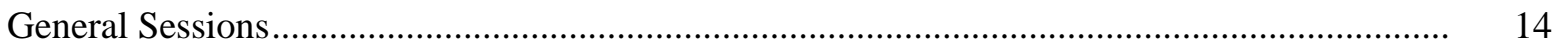

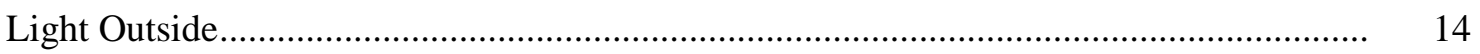

Summary of Key Ideas: What did we learn from all of this? ............................................ 15

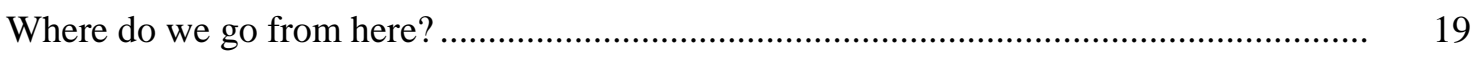

Appendix A SSL in Higher Education Workshop Agenda ............................................................. A.1

Appendix B Attendee List .......................................................................................................... B.1 


\section{Figures}

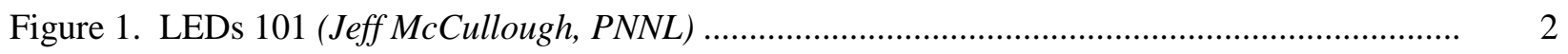

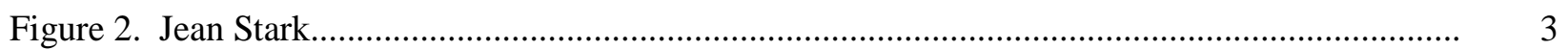

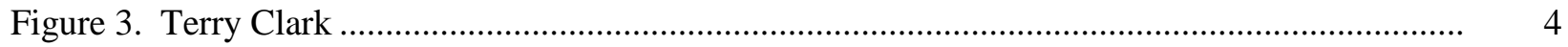

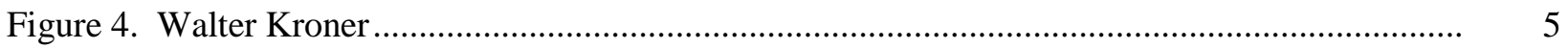

Figure 5. Panelists Stark, Clark, Burkett, Kroner ..............................................................................

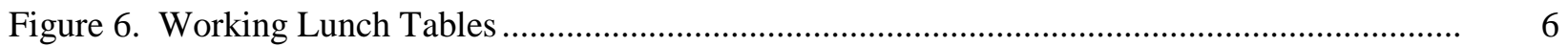

Figure 7. Randy Burkett and Marc Ledbetter ............................................................................ 9

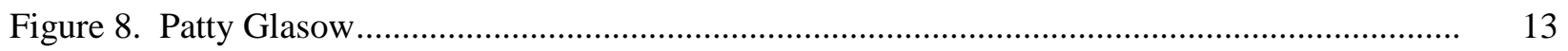

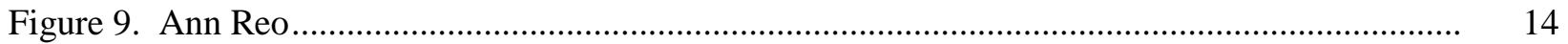

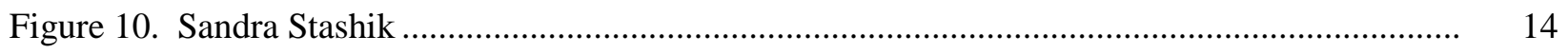

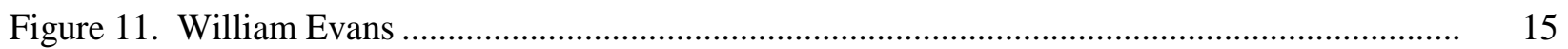

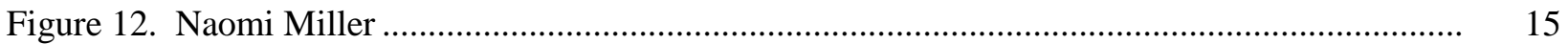

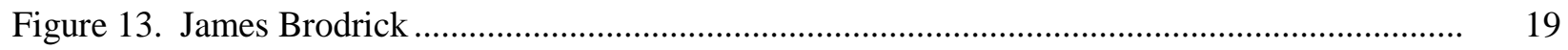




\section{Introduction}

The Portland workshop was funded by the American Recovery and Reinvestment Act of 2009. The purpose was to jumpstart a candid conversation among SSL luminaire manufacturers and the people who specify, purchase, install, and maintain SSL luminaires. To that end, workshop presenters included lighting designers, engineers, and facilities managers, with the audience consisting principally of SSL fixture manufacturers, component manufacturers, and affiliated industries. The workshop was designed to blur the line between presenters and attendees and was intended to be loose and interactive, rather than the "we talk, you listen" variety. Everyone was expected to participate in identifying the thorniest existing product design issues, and constructively develop solutions on improving the quality, functionality, and sustainability of SSL fixtures. A further goal was that the discussions and ideas generated at this workshop would inform DOE's understanding of the current state of the industry and market adoption, and help DOE's planning on what resources or research are needed to move the whole industry forward. A diversity of SSL industry players discussed their challenges, and many dynamic ideas and inventive solutions were contributed.

The focus of the workshop was on higher education facilities because college and university campuses are an important market for lighting products and they use almost every kind of luminaire on the market. In addition, higher education facilities are complex, and are, in many ways, like a small city, with lighting applications that run the gamut from classrooms and offices to theaters, labs, libraries, dormitories, dining halls, museums, chapels, outdoor walkways, parking lots, garages, lecture halls, indoor arenas, and outdoor stadiums. Their facilities need to communicate an image and philosophy, while being functional, maintainable, and sustainable. This kind of focus provided an ideal springboard for discussions that cover as broad a range of product types and application issues as possible. This workshop was seen as a chance for SSL manufacturers large and small to get the inside scoop from a group of people that specify, pay for, install, use, maintain, and dispose of lighting systems for nearly every type of application. Workshop attendees explored the barriers to SSL adoption, the applications where SSL products could work better than existing technologies, and where SSL luminaires are currently falling short.

To ensure that the workshop was both highly interactive and productive, the size of the workshop was limited, and SSL manufacturers were encouraged to send only one attendee - ideally the individual who directs product development and can best represent their company's perspective on both engineering and design issues.

Appendix A is a copy of the workshop agenda. Links to all the presentations can be found at http://www1.eere.energy.gov/buildings/ssl/higher_ed_workshop2010_materials.html. 


\section{DAY 1 - Tuesday, May 25}

\section{"Live Long and Prosper?" Where do LEDs make sense in the energy efficient lighting world? \\ Heidi Steward, Pacific Northwest National Laboratory}

\section{Solid-State Lighting Basics}

Jeff McCullough, Pacific Northwest National Laboratory

The Workshop began with LEDs 101, a two-hour introduction to the technology, terminology, metrics, photometry, standards, and CALiPER testing of LED products, including chips, modules, drivers, power supplies, and controls. Presented by Jeff McCullough and Heidi Steward of PNNL, this spurred many questions and comments from the audience. Here are some of the most important:

1. Vocabulary. In spite of standardization by IES $\mathrm{RP}-16$, the industry is still using inconsistent, imprecise, or incorrect terminology for LED

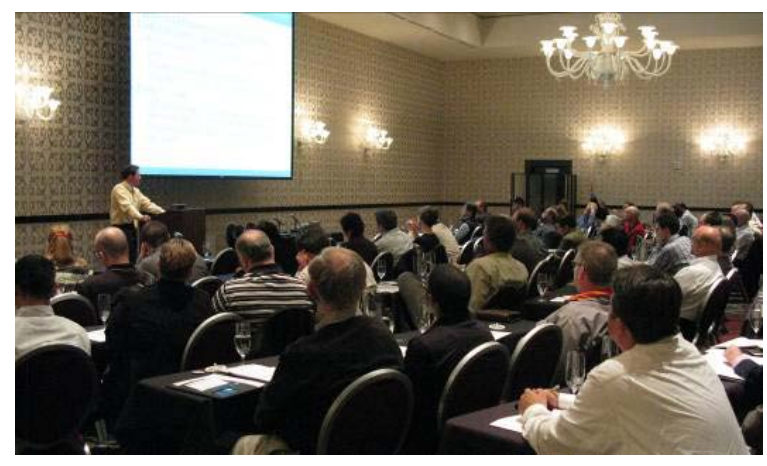

Figure 1. LEDs 101 (Jeff McCullough, PNNL) products and components.

2. Terry Clark of Finelite noted that there is a Milspec (i.e., Military Specification) available for LED drivers. Is that incorporated into the L-Prize criteria? (Answer from JM: Not at this time.)

3. Jeff Miller asked if embedded energy is evaluated in CALiPER testing. For example, is there any documentation of energy used to manufacture the several pounds of aluminum used in heat sinks? (Answer from HS: Not at this time.)

4. The LM-79 and LM-80 testing of LED products is very costly and time-consuming for the manufacturer. It is impossible for them to test every permutation of every product. Is there a way to generate a single LM-79 report and apply multipliers for different drive currents, chips with different CCTs and CRIs and lumen outputs? (Answer from JM: Although the ability to apply such multipliers would be immensely useful, there are far too many unknowns about LED technology LEDs, electronics, materials, etc. - to develop the data needed to establish them today or in the near future.) 


\section{DAY 2 - Wednesday, May 26}

\section{General Sessions}

\section{Introduction and Welcome}

Dr. James Brodrick, Department of Energy

Dr. Brodrick encouraged the audience to engage in conversation rather than traditional lecture-listen format.

\section{Lighting Design: the Barriers to LED Adoption \\ Jeff Miller, Pivotal Lighting Design}

Whole building design — designing lighting for a building is a holistic process, not a linear one, and the lighting used depends on the application.

Lighting Designers (LD) are technology-neutral, they are going to select the lighting source that makes the most sense for the lighting application and will select LEDs when they deliver the most appropriate light output, color, light distribution, controllability, cost, and other characteristics. LDs are not technologists or researchers, not interested, don't have the time to sort out the problems. They really rely on luminaire manufacturers to do that for them.

UN definition of Sustainability: environmental protection, economic development focusing on the welfare of the individual, and social equity. In short, a sustainable now and sustainable future.

Lighting is designed in collaboration with all the other partners in the design process.

“The $2 \mathrm{x} 4$ troffer is not a light fixture, it's a real estate solution.” Lighting designers have spent 40 years working to eliminate ugly, inflexible, and inappropriate fluorescent 2' x 4' luminaires, and now manufacturers are pursuing the same dumb ideas, this time using LEDs rather than fluorescents. If it is not working to make the lighting better, who needs your technology?”

Good lighting uses layers of light, not single source solution.

\section{More than Watts and Footcandles: Designing, Building and Maintaining Attractive and Effective Spaces} Jean Stark, JMZ Architects

"Millennial" students are pushing the agenda on campuses, and students are looking for these kinds of challenges and solutions. They are socially and environmentally conscious, and are invested in the idea of teamwork and collaboration.

The Presidents' Climate Commitment, signed by 673 campus

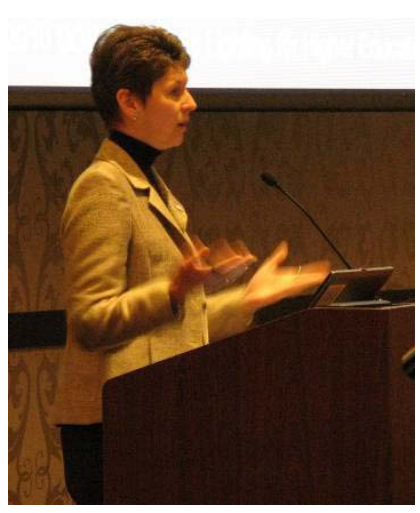

Figure 2. Jean Stark 
presidents so far in the US, is a movement to get colleges and universities to move towards carbon neutrality. It requires planning and working towards really ambitious goals. Lighting becomes a major focus on the way to achieve these carbon reduction targets.

Economics on a campus are different. Campuses have the luxury of looking long term, because they own their own facilities and pay their own energy bills. They can make serious up-front investments, but are very much focused on first cost and life-cycle costs. They are more likely to have a cradle-to-cradle perspective than many commercial facilities. Faculty, students, parents, donors, and corporations sponsoring research do not tolerate sub-standard spaces.

Facility departments need a really compelling reason to shift to a new lighting technology; in general they have already hit the low hanging fruit with recent energy retrofits to screwbase compact fluorescent lamps, T8 lamps, and electronic ballasts. The shift to LEDs must show rapid payback and/or lighting quality improvements, or it will not be considered.

\section{Here are the Constraints: Manufacturing POV}

Terry Clark, Finelite

Hype is a fundamental problem that needs to be addressed by the industry. Linear fluorescent lamps are a mature, high-performing, consistent, and reliable technology, and as such it is a tough competitor for LED products. Venture capital and its funding of the semi-conductor industry has changed the dynamics of the lighting industry, and its focus on getting a return on investment means that there is less of a focus on getting the technology working reliably for the longer term and developing standards. This means early adopters are getting burned and these early results with bad products are resulting in very bad blowback against the technology as a

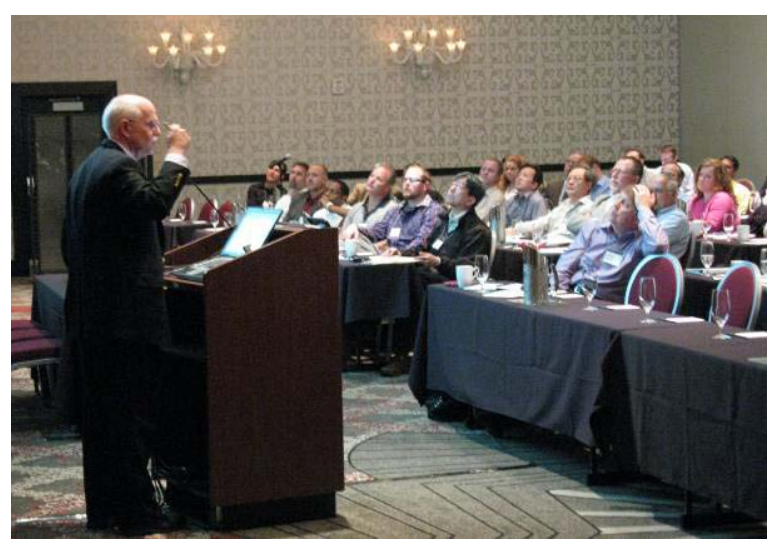

Figure 3. Terry Clark whole.

Every component has to work flawlessly together, and at the moment, they don't, and the luminaire manufacturer must spend enormous sums fixing field problems. We are missing some key standards: TM-21 (method for extrapolating long term lumen maintenance based on LM-80 testing) still is 2 years away, and we don't have a way of knowing when an LED product is "dead”. Fluorescent lamps stop working when they're done, but LEDs continue to emit light long after the efficacy and light output have decayed badly. Who decides when the LED products are to be replaced, and who is responsible for the increase in maintenance costs? LED Luminaire manufacturers need to focus on applications and the best practices for that application, and design/engineer to meet those.

\section{Light and Systems}

Walter Kroner, Rensselaer presenting Oliver Holmes’ talk

System View: We commission an HVAC system, why aren’t we commissioning lighting systems? 
Skill level: a completely new skill level and course of training is necessary for installers and commissioning agents and maintenance workers. Electricians, for example, are not skilled at electronics, and may need different training to install and maintain LEDs.

Language: every specialty speaks their own language, and if one group cannot communicate with another, then the listener will stop listening. Manufacturers must understand how to reach everyone you deal with, or your product and your message are dead on arrival. The languages used by an LD, electrical engineer, architect, and electrician are all different. Some may respond to text, some to spreadsheets, some to diagrams, others to pictures.

Labeling and instruction sheets need to consider human factors (size, contrast, color of text and graphics so they are READABLE).

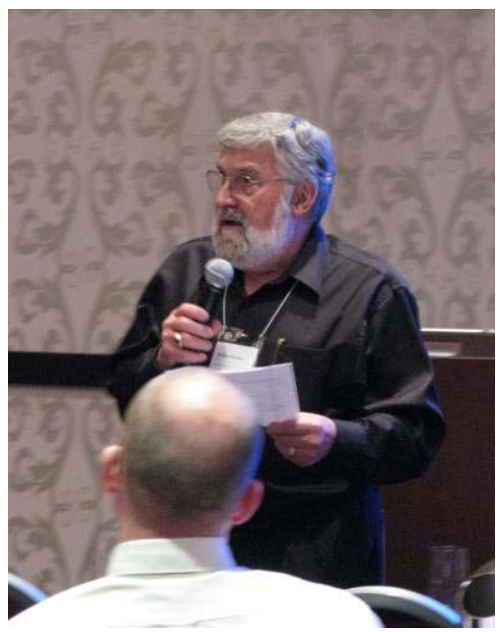

Figure 4. Walter Kroner Product labels need to be permanently attached so they don't fall off. Manufacturers, are you making it easier or harder to install and use your products?

\section{Light and Systems}

Randy Burkett, RBLDI

Lighting Designers (LDs) have to reeducate clients because of the amount of hype.

LEDs are appropriate for only a limited number of applications at this point in time. These include:

- Task lighting

- Cove lighting now, wall washing (soon), and curved surfaces or slots or lettering now

- Tiny lighting needs, where only a small amount of effect lighting is needed

- Glamour projects, especially those with color and color change

- Façade lighting, and exterior street and area lighting

Inappropriate applications include laboratories (except task or undershelf lighting), classrooms and lecture halls. LED retrofit lamps are not quite ready for widespread use for accent lighting, but are not far off.

The LD is a master mason, rather than knowing every detail of all products and installation. The LD must know and manage the client's needs and expectations. 


\section{Panelists Facing the Firing Squad}

Q: When the design process takes five years or more and LED products evolve so quickly, how do you specify or budget for LED products that don't yet exist?

A: Write performance specs, asking manufacturers to meet these performance goals. This is difficult because most LDs don't know how to describe and qualify all the aspects of the new technology.

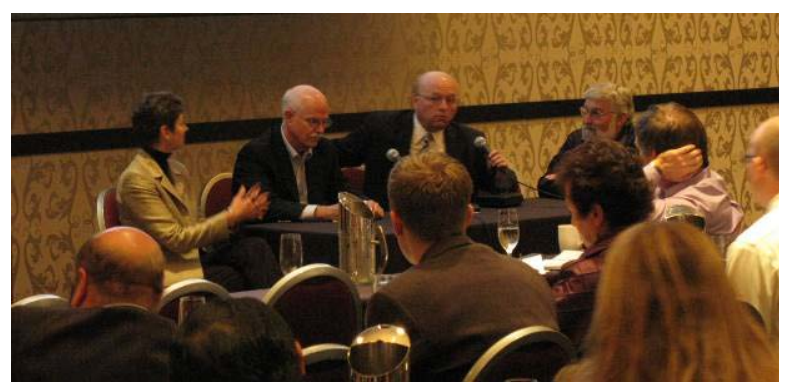

Figure 5. Panelists Stark, Clark, Burkett, Kroner

Q: Can we learn from other industries how to advance LED adoption into architectural lighting products?

A: In the electronics industry, so many companies went bankrupt because they were addicted to the idea of the technology, rather than the best practice that the technology advanced. The technology will not change what should be lighted or how. The building industry and the SSL industry operate at very different speeds, and the integration of the two industries is difficult. The building industry is interested in stability, whereas the SSL industry is fascinated by the newest thing, and is very comfortable with creative products that are quickly obsolete. The construction industry is not an early adopter, and cannot afford the instability of constant change, especially considering the prolonged lifetime of a building and the expense and difficulty of changing out lighting as needs change.

\section{Working Lunch Topic Tables}

Participants were asked to sign up for a lunchtime topic table of personal interest. These topic tables were meant to be brainstorming sessions, and participants were asked to pick a topic that they were passionate about and felt that they had constructive ideas to contribute about. Topic tables were led by one of the speakers, and facilitated by a representative of the Pacific Northwest National Laboratory.

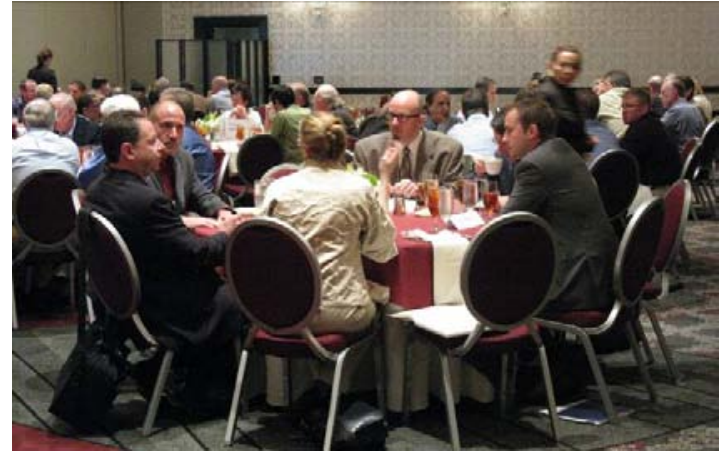

Figure 6. Working Lunch Tables

The Topics and Summaries of the discussion follow here.

1. LEDs, Controls, and Compatibility. Summary:

- Problems include flicker, flashing, step dimming (not smooth), malfunction, instability or shutoff at lowest end of dimming. "Dimmable” on product cutsheets often means “Doesn’t dim well.”

- Identify end user requirements of dimming performance: smooth and quiet transition, and percentage of dimming, i.e., $1 \%, 5 \%, 10 \%$ etc. Manufacturers need to assist with technical writing for performance specifications for all components. 
- Emulate high tech industries and hold an annual event to address interoperability. Proprietary systems work against cooperation, and no one wants to stifle innovation, but there is a real need for cooperation and communication among manufacturers to create standardization in the industry. Can we standardize the different approaches to dimming (i.e., PWM, sine wave dimming, Triac, SCR, DC dimming, 0-10V fluorescent dimming, etc.)? Products that meet established standards are more likely to be compatible.

- $3^{\text {rd }}$ party compatibility testing was recommended, similar to CALiPER.

2. Snake Oil origins: Geek Speak vs. Sales Spin. Summary of discussion from table:

- Basic consumer education is an area that clearly needs work. Consumers need access to a more standard vocabulary - more than Lighting Facts - that would allow them to understand lumens, equivalent wattage, distribution, etc. Often that information is not available from manufacturers, because their marketing departments don't understand the vocabulary either. Within companies information is not always moving between the engineering department and the marketing department (the marketing departments do not know that the chip level values for LED performance don't carry through to luminaires). Although this is not just an LED issue, education is needed here as well.

- The group wanted complete quantitative performance specifications to be available, not just lumens/watt. These specification needs may vary based on the viewer. The retail consumer needs a smaller subset including lumens, comparison to an equivalent incumbent, and basic distribution information. The distributors and lighting designers need to understand what they're getting from manufacturers at the system level with trade-offs/priorities available. Luminaire manufacturers need to be able to get clear information from component representatives about the LEDs, drivers, and other components.

- A standard form is needed for reporting performance data, including blanks where a manufacturer opts NOT to report data.

- Standardization of parts and pieces shouldn't crush innovation, but it WOULD allow swappable components. This is one benefit of performance specifications. The auto industry went through a similar transition when performance specifications were introduced.

3. Snake Oil repercussions: Fraud, Credibility, \& Responsibility. Summary of table discussion:

- Wild claims of performance hurt the entire industry and run the risk of alienating lighting designers and end-users from the technology, ultimately slowing market penetration. Until such time as we have a significant installed base of products that have operated for enough hours to verify initial claims, we will continue to have this problem. It is in the best interest of mainstream reputable manufacturers to encourage responsible reporting and draw attention to exaggerated claims. They need to lead the way for the industry.

- Possible solutions included: 1.) Having (or requiring) the chip/package manufacturers take more responsibility for their customers' claims. This includes certification programs, possible review of customer marketing materials, providing more data (LM-80/life projections), etc. 2.) Manufacturers must demonstrate that they have designed/engineered the luminaire to substantiate their claims of life. Specifically in-situ temperature measurement testing (ISTMT) or other industry-recognized reliability testing. 3.) Develop design guides/submission requirements for lighting designers so that we begin to reinforce the same set of requirements across the industry and luminaire manufacturers know what 
is expected of them. 4.) Have the government take a more aggressive role in regulating claims and challenging marketing materials and, if necessary, prosecute offenders.

- Lighting designers and engineers have legal responsibility for building safety. Who is responsible for product failure on a project? Designer? Engineer? Component manufacturer? Luminaire manufacturer?

- What if all companies used the same components? Interoperability would ensure less risk.

- Design guidelines are needed to distribute collective information on specifying and using LED products.

\section{Fluorescents v. LEDs: Performance and Economic Reality? Summary:}

- A facilities manager from the University of Maryland shared a dose of reality: He said that he is inundated with salesmen that are selling 4-foot LED replacement lamps to his department, his boss, and his boss's boss. Tens of thousands of these 4-foot lamps are already in the US. They need to find sockets. Sales people are desperate to close an order. These salespersons will make whatever claims needed to get installations going. It is raw and messy. And, it is a ticking time bomb. Most specification-oriented specifiers, engineers, and manufacturers are either unaware of this or they feel they are generally above this retrofit world.

- LED T8 replacements have flooded the lighting marketplace, driven by investors and manufacturers going after millions of existing fluorescent sockets - a (seemingly) easy "twist-in" retrofit opportunity. This abundant low hanging fruit feeds the enthusiasm and resulting hype, which is relayed to lighting practitioners directly via marketers - and often indirectly via their own management, who have been caught up in the excitement and misinformation. Independent testing (e.g., DOE CALiPER) and growing field experience are showing that LED T8 replacements fall far short of linear fluorescent on efficacy, performance, and cost-effectiveness.

- Fluorescent isn't just about linear lamps, however. CFLs, commonly used in downlights, are not as efficacious as linear fluorescent, and can be problematic in their color quality and dimming. Unlike 4-foot linear fluorescent systems, they are not as big or as tempting of a retrofit target. However, LED integral luminaires are proving to be viable alternatives in CFL applications.

- Unfortunately, the fluorescent applications where LED fixtures can make sense (e.g., downlights, 2'x2's) are being overshadowed - and potentially tainted - by the LED T8 replacement frenzy. First impressions count! The group recommends that DOE be more direct in its criticism of and warnings about bad LED products and applications, and leverage its communication tools and media contacts to broadcast the message to as broad an audience as possible.

5. Outdoor Lighting: What *could* these lights do? Summary:

- The use of lower light levels triggered by occupancy sensors remains a primary safety concern.

- Induction lighting is competitive with LEDs in cost and performance for lower pole heights. LEDs can't yet compete with HID for taller poles (50’ to 100' in height).

- Designer/engineer must design for worst case condition over time, with adaptive controls dropping light levels when conditions permit.

- Feedback on \# of burning hours is important for planning maintenance, especially on light source that doesn't burn out. 
- Premature LED failures have occurred due to water infiltration of outdoor luminaires.

- A 5-year warranty is very important. Does it include the fixture or only the components? Does it include labor?

- Standard testing is needed on dirt accumulation on heat sinks, high ambient temperatures for Phoenix, Abu Dhabi, etc.

6. Outdoor Retrofits: How to assure equivalent performance? Summary:

- Application efficacy is a recognized need, as opposed to mere luminaire efficacy. The DOE Municipal Solid-State Street Lighting Consortium will address this. The manufacturers asked for an update on the status of the draft ENERGY STAR criteria for outdoor LED luminaires, and were informed that the criteria remain on hold while DOE works with NEMA to explore the possibility of creating a metric superior to FTE. The manufacturers expressed frustration with the "moving target" but also encouraged DOE to shift the focus from luminaire efficacy to application efficacy.

- Is it better to replace the whole luminaire head, or retrofit the interior parts? Answer not clear yet. The new luminaire is better optimized for performance. The retrofit kits can sometimes be glaring.

- The impact of retrofitting acorn-globe fixtures with cutoff retrofit optics seems generally acceptable, even though it may render facades and tree canopies less visible.

- Often lighting measurements are not taken after a retrofit, so relative performance is not recognized as an issue. Meeting IES recommendations is not necessary for all applications.

- A broad spectrum is good for outdoor lighting, and cool CCTs brighten appearance, even though the IES does not condone reducing light levels when delivered by bluer sources.

- Many of these issues will be addressed as part of the new DOE Municipal Solid-State Street Lighting Consortium:

- Compilation of available products and associated data

- Compilation of criteria from a variety of municipalities

- An opportunity to implement application efficacy requirements (in lieu of luminaire efficacy)

7. Quality of Light and Market Acceptance Chief lighting quality concerns include:

- Glare - need to characterize the source better than a point. Consider using a glare metric system similar to tunnel lighting, including luminance of the surroundings. Remote phosphors will help reduce glare. Indoor and outdoor glare need separate metrics. Glare not necessarily the hottest issue, but it is significant.

- CCT - Too many manufacturers are pushing high CCT LEDs because of high efficacy. Long term color maintenance is a big issue because customer confidence in a product is damaged by color drifting.

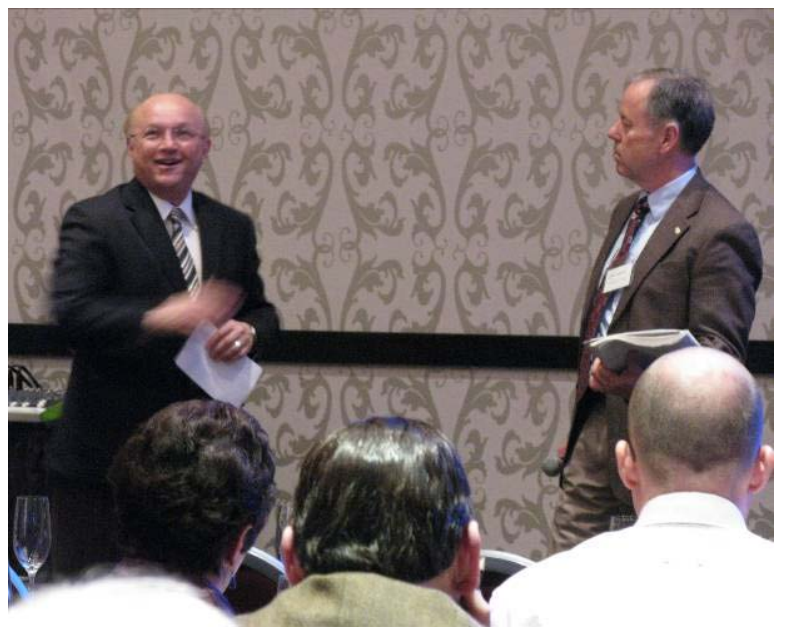

Figure 7. Randy Burkett and Marc Ledbetter 
- CRI - gives heartburn to the table. CQS is a better metric, but it doesn't replace the eyeballs for color rendering ability. Consensus at the table was that there is too much emphasis on $\mathrm{lm} / \mathrm{W}$, and not enough on color quality.

- Flicker - Not a big problem yet, except when LEDs are dimmed. Should LED color shift to red when dimmed (similar to incandescent)?

8. Sustainability and End of Life: Which Recycling Bin? Summary:

- The general public has the perception that LEDs are a sustainable alternative to all other kinds of lighting. As a result, there is increasing pressure on colleges and universities to install LEDs for a wide variety of applications, and institutions are eager to reduce their carbon footprint by investing in energy efficient technologies. The question must be asked, however, whether LEDs are truly a sustainable solution. For example:

- Are toxic chemicals used in the production of any of the LED components?

- What is the carbon footprint (greenhouse gases [GHG] produced) during manufacture and shipping of all components?

- $\quad$ Are the fixtures/components recyclable?

- Are there heavy metals in any of the components?

- If the LED has an expected life of 55,000 hours, does the rest of the assembly have the same anticipated life?

- Does it really make sense to replace a proven technology with LEDs, or should we be focusing on the kind of uses that make the most sense for the technology?

- An example: If a linear fluorescent troffer is rated for 100,000 hours, which makes more sense over the life of the fixture: 3 lamp changes with a T-8 fluorescent lamp, or replacing an entire LED fixture twice? Which is really the more sustainable option?

- It would be really cool if:

- Fixtures/lamps had labels that provided the designer/end user with GHG data, information about heavy metals in the unit, and/or embodied energy data. Sustainability rating systems already try to track things like mercury, certified wood, and formaldehyde. If LEDs can be shown to be more "green" than other lighting options, they will be embraced more readily.

- Manufacturers worked together to fund a comprehensive recycling program for LEDs (potentially funded by adding pennies per unit sold), that made it easy for end users to recycle their products.

- Manufacturers standardized LED components!

- Individual components of LEDs could be replaced instead of throwing out the entire fixture.

- Individual LED components in a fixture had similar expected lives, so equipment that is still good didn't have to be trashed.

9. Warranties, Durability, \& Service Issues. Summary:

- One of the main issues with warranty is thatresponsibility for addressing performance and warranty issues is unclear. Since these products are an integrated system, if one of the components fails, who 
is responsible? There can be a lot of finger pointing. Reputable companies generally will pay to fix the product to ensure the customer is happy. However, with all of the start-up companies producing LED products now, a customer needs to be especially careful to investigate whether the company is likely to be able to stand behind their warranty. One challenge is that customers sometimes use products in applications for whichthey are not well suited and which are outside of the guidelines for their use (i.e., an area that is not ventilated, causing the lamp to overheat).

- In large projects it is advisable to "commission" the work to ensure that the product is correctly installed. This will help ensure that warranty issues do not arise down the road.

- Another issue with LED products is that when a luminaire fails, you may not be able to get the "same" product as a replacement. Often times it is NOT the LEDs that fail, so the manufacturer can fix the failed component, leaving the original LEDs intact. If the LED cannot be recovered, then it could be hard to match color - which is important in cases where color match is critical to the application.

- Manufacturers are concerned that LED products are held to a higher standard than other lighting products. But there is recognition that consumers expect more because the technology is new, more expensive that traditional technologies, and long term performance is unproven. The group agreed that warranties should be 3-5 years. There is a cost associated with a longer warranty, so the customer that demands this should expect to pay an upcharge for the extended warranty. The customer needs to know that labor is generally not covered by the warranty.

- Specifiers need to alert the client that LED products must be accessible and require experienced installation/commissioning. Standard electricians do not have the required skills.

- Component manufacturers must support the luminaire manufacturer. LED chips almost never fail. Rather, it's a component failure that causes the field problem. What do you do when a product fails? What component has failed? How do you know which manufacturer to contact?

10. Standards + Specs: What needs to be written? Summary:

- LM-79 is useful, but is no guarantee of performance. Likewise, LM-80 is limited and provides little useful information about lifetime and reliability of luminaires or systems. System lifetime and reliability was seen as a key needed standard, as well as standardization of controls, drivers, and power supplies.

- The NEMA SSL controls committee is working on a dimming standard. To date, the committee has published a white paper (LSD 49-2010), "Solid State Lighting for Incandescent Replacement-Best Practices for Dimming," which lays out issues specifically related to LED products intended to replace incandescent sources on existing dimmers.

- There is a need for standardized interfaces. The Zhaga Consortium has formed to address this topic at the international level.

- Standards related to color quality are also very important; the color quality scale (CQS) will be a future improvement, but also needed are metrics by which to verify color stability over time and differentiate color quality needs for different applications, as well as better language and labeling practices to communicate color quality to consumers.

- Better understanding is needed of human and environmental impacts of LED lighting systems, including flicker, radio frequency interference, and material and production sustainability and 
recycling. More research and better understanding of these issues will likely lead to the need for and ability to define new metrics and standards.

\section{Specifying \&+Installing: How to assure that Chips + Bits + Parts + Pieces will work well together?}

- The LED product needs to be specified as a system (including the wiring connectors), not a kit that is assembled on the job site. Is UL listing required on all components?

- Electrical contractors are not trained to install LEDs (i.e., electronics). A special installer, similar to an AV specialty contractor, should do the installation. But this adds cost and complexity.

- Where is the driver in the system? How would the owner know to replace it if it has failed? The driver should have polarity protection and load detection built in, if that would damage the system. Manufacturers of parts need to do a better job of explaining what each part does, since every LED is different.

- Standards are needed for wiring colors, guides for wire gauges, and interchangeable parts. These standards could be similar to BACNET in the HVAC world.

- Standards for LEDs should target lumen output, light distribution, and color for future upgrades. Remote phosphors allow a CCT change without changing out LEDs.

- Class II power supplies are safe, but are they good for performance?

- Low-voltage DC distribution systems are impractical until buildings are fully solid-state.

\section{General Sessions (cont'd.)}

\section{Light for Brains}

Chad Groshart, atelier ten

Chad described lighting for a museum of jars of preserved brains at Yale Medical School (Really!). There were critical archival demands (no UV or IR, tight space restrictions, strong directional light with a narrow distribution needed, dimming required) that LEDs satisfied superbly. He agrees that a 3+ year product warranty is necessary, and the designer needs to know how long the company has been in business before accepting that warranty.

\section{Light for Brains}

Christie Day, Yale Medical School

The Yale Medical School facilities undergo $\$ 50$ to $\$ 80$ million of renovation per year, and are remodeled with a tight time turn-around, depending on NIH grants and what the medical researchers need. YMS has developed their own design standards for these remodels, LEED integrated and sustainability goals included. The President of Yale has signed the President's Climate Commitment. Occupancy sensors don't work well in their experience, and there is a lot of resistance to their use, which means many lights are continuously on. In many cases, the researchers hate the lab lighting, and improvise their own task lighting. There is little space above ceilings for lighting and electrical. There is no time to do mockups, because sample fixtures do not arrive in time, so decisions are based on cutsheets. Her wish list for lighting: 
- Fixtures should be sealed and gasketed so they do not admit contaminants. They should be easily accessed and maintained even by staff with big hands. It is a problem maintaining ballasts mounted on top of recessed fixture housings, because the whole fixture must be removed from the ceiling.

- Product literature has to show all operable conditions of the fixture, so that conflicts can be anticipated.

- Shallow-profile surface-mounted fixtures are needed, and are missing from the marketplace.

- Longer-life lamps, improved daylight, and occupancy sensor controls are needed.

\section{A Shot of Reality with a Chaser of Inspiration Patty Glasow, Auerbach Glasow French}

As a lighting specifier, Patty has over 10 years of project experience specifically with LEDs. She toured us through the design and construction process on several projects, with "Notes to Self” to identify what was learned on each one. A summary:

- Since LDs are responsible for light levels for life safety codes, LEDs that drop in light output but never die are a problem. She'd like a "kill switch" option based on predetermined light output, so that the client knows when the fixture is dead.

- Writing the 3-name specification required on many public university projects is virtually impossible with proprietary LED systems. Competing products

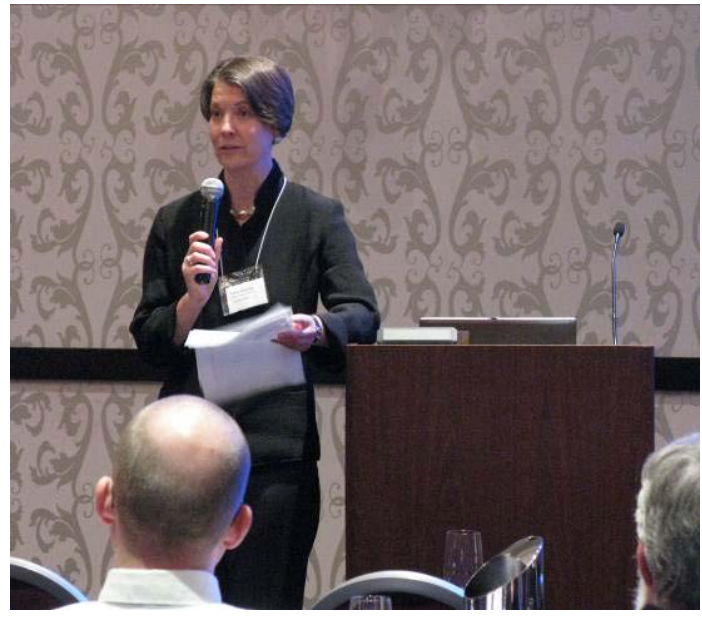

Figure 8. Patty Glasow simply aren’t comparable or interchangeable.

- If a luminaire manufacturer knows about heat problems with their LED products, they should warn the specifier about enclosed fixtures or insulated ceiling (IC) locations.

- RGB color mixing produces poor color rendering.

- A professional integrator is absolutely necessary for a sophisticated LED lighting and controls installation.

- LEDs operated on an architectural dimming system may flicker even when the dimmer is set to NonDim.

- Think about application efficacy, not just luminaire efficacy. Does the lighting system put the lighting only where it is needed?

- Designers want standard products to specify, not bits and pieces that need to be integrated. 


\section{A Shot of Reality with a Chaser of Inspiration}

Ann Reo, io Lighting/Cooper Lighting

Ann, founder of an LED luminaire company in 2002, has much experience from the manufacturing side. Along with the photogenic successes, she has learned many tough lessons. Since the beginning, io lighting has inspected every LED by eye for color, since color binning is so poor. The best they can buy is a 3-step Macadam Ellipse. ANSI binning is not tight enough for lighting on a white surface. She recommends $+/-50 \mathrm{~K}$ maximum. She likes LEDs for cove lighting because it minimizes the shoddy appearance of burned-out lamp. LEDs are ideal for elevator applications

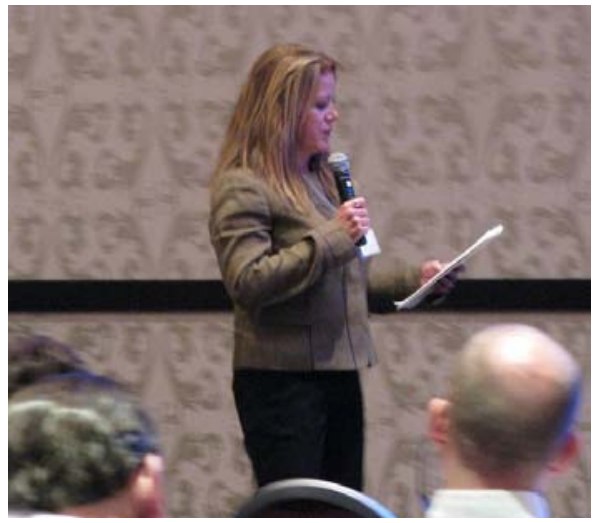

Figure 9. Ann Reo because they are resistant to vibration. She warned that Energy Star can overemphasize luminaire efficacy at the expense of glare for users.

Manufacturer cut sheets should have installation and construction attributes listed, but mockups are still essential. Her company provides samples for mockups to reduce risk for the specifier and client. Recommendations: Make sure the luminaire is rated for LED replacement lamps before specifying them. Use LM-79 reports and Lighting Facts labels for accurate performance information.

\section{DAY 3 - Thursday, May 27}

\section{General Sessions}

\section{Light Outside}

Sandra Stashik, Grenald Waldron Associates

Lighting design requires focusing on meeting criteria first, not focusing on the light source as a starting point. LEDs should be specified only where they make sense. When designing with LEDs, specifications have to be so much more detailed, digging into components in a way that is unnecessary with other technologies.

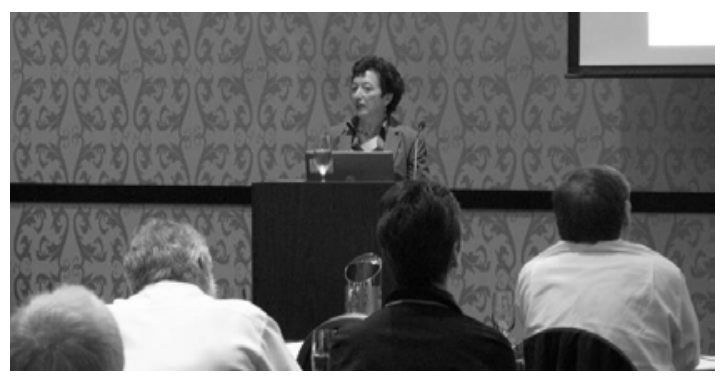

Figure 10. Sandra Stashik

Quantity and quality have to be balanced.

Luminaires with wider spreads of light may look energy efficient because they can be spaced farther apart, but these fixtures are also more glaring, and glare wastes energy. Dark sky sensitive design may need to be balanced with a little bit of uplight for a sense of safety. Cutoff, light pollution, light trespass, directed optics, and visual interest are all important considerations.

LED failure issues she has dealt with: water, temperature, connections. The big cost of outdoor lighting is in the installation, not the product. She often prefers lower height poles because their light is unobstructed by the tree canopy. Textured globes on LED decorative post-tops luminaires helps obscure the distracting LED arrays. 


\section{Light Outside}

William Evans, Princeton University

Princeton University has a 260-year history, and has very high expectations for quality and appearance and service to the world. Local town officials are also concerned about maintaining a rural campus look, so they are involved in infrastructure decisions. Princeton has very strict goals to cut GHG emissions, but is also increasing the number of buildings on campus, so meeting the fixed emissions goals is challenging. $25 \%$ of these energy savings are yet "To Be Discovered".

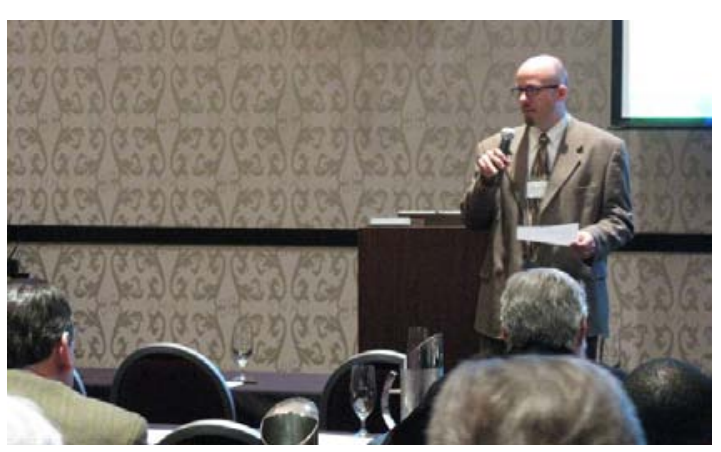

Figure 11. William Evans Alumni are helping fund sustainability drives, involving students. Goals for lighting may conflict: new technology, but predictable performance and reasonable payback on investment is required. Ideally all lighting products would exhibit long life, including lamps and components, easy stocking of parts, and a 20-year system warranty. Quick disconnects are important for replacement parts. Princeton wants to reduce nighttime light levels but with no increase in crime. He'd like addressability of luminaires and controls, but without the complexity that comes with them, and the risk of the company's going out of business. The proprietary nature of control systems and their incompatibility makes him long for standardization of protocols and communication.

He proposed thinking outside the proverbial box: Can we adjust behavior of users to compensate for reduced lighting outdoors? For example, illuminate fewer paths at night, encouraging users to take the lighted, safer routes. Encourage pedestrians to carry personal flashlights. Instead of asking, "How do we add lighting to this parking lot?” we should ask, "How do we separate pedestrians from the cars so that lower light levels are adequate?”

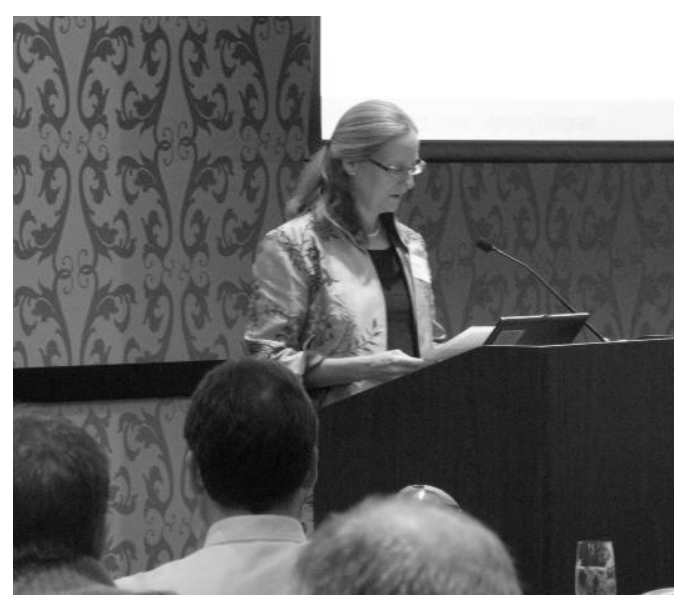

Figure 12. Naomi Miller

\section{Summary of Key Ideas: What did we learn from all of this? \\ Naomi Miller and Ku'uipo Curry, PNNL}

This section of the report captures the essence of the speakers' messages, and does not necessarily represent the views of the U.S. Department of Energy.

\section{Specifications}

- The designer/engineer designs for the application, not the light source. He/she designs to solve a problem, not to use an LED product.

- The designer/engineer needs to prepare the client and contractor for the additional effort and cost that it takes to get LEDs installed and functioning. The lighting designer should outline the work, coordinate with the luminaire manufacturer, and suggest mockups and practice runs to avoid 
problems. This level of effort needs to be included in the design fee to get everyone on the same page.

- Trust is important among all design team members, and that includes the luminaire manufacturer.

\section{Communication and Education and the Federal Government}

- What does the LED product data mean? What does "lifetime" mean? We need to educate the user, designers, engineers, representatives, and manufacturers. We also need to make sure that information is not garbled when transferred from the engineering department to the marketing department at the luminaire factory. This will help reduce hype from unknowledgeable marketing departments.

- Electronic-speak vs. lighting-speak vs. user-speak: We have to work to communicate in a way that the audience will comprehend. Know the language of your audience. Product literature may need to include photos, drawings, 3-D perspectives, or links to videos to explain the features or installation to people who respond best to pictures.

- Hype is a critical issue that could destroy the public's perception of LEDs. Marketing literature for higher-end manufacturers should communicate higher goals (excellent color rendering, high reliability, low flicker, long warranties, etc.) to differentiate the better manufacturers from the lesser ones.

- The group would like to see design guidelines developed for using LEDs, to amass collective information that will help bootstrap all designs and installations.

- We would like the DOE to go back to the federal government to broaden the mandate for LED development to include components/drivers. That is the current weak link.

\section{Luminaire Manufacturers}

- Manufacturers need to stand behind their fixtures, providing robust components and electronics, warranties, easy installation and instructions. Manufacturer must take full responsibility for the product and components to reduce finger-pointing, but that means they need support along their supply chain.

- They need to understand that electricians are not trained in electronics, so they do not understand DC wiring, series wiring, fussy connectors, sophisticated programming, or interfaces with controls, and they often can't read small point type. It may be necessary to hire a specially trained contractor or a commissioning contractor. (But it IS possible to print instructions in 12-point type with diagrams on full-size paper!)

- Manufacturers need to collaborate to create new rules of the game to deal with LED problems and issues.

- They need to do their own carbon footprinting of their products and processes. There are many notfor-profit carbon footprinting organizations (run by millennials) that can help with this.

- DOE LED NASCAR competition: manufacturers could do extreme testing, taking on a challengedesigning to military specifications, for example, with components that can last. Set a goal of designing products that the US Air Force will accept. 
- How do manufacturers stand behind a product? How do they respond to failures? How do they take care of the customer? Manufacturers need to huddle together and figure this out.

- Consider a cross-functional product design team with the strength of a diversity of opinions, backgrounds, experience, and points of view. (E.g., marry electronics with bullet-proof product design.)

- Proprietary IP is a key driver of the silicon industry, and that attitude is invading the traditional lighting industry. It tends to produce a short-term focus, so we need to learn how to manage it for long-range clients such as college campuses. Venture capital firms that came out of Silicon Valley are changing the dynamics of the lighting industry, looking for fast profits from underperfected products.

- LED products must be manufactured as a system, not a series of separate parts, in order to ensure compatibility and one point of responsibility when it's installed.

- Some components will fail. Can manufacturers plan for replaceable parts with identical performance in the future? Can a longer warranty be provided for an additional cost to the client? Can the risk be shared between owner and manufacturer?

- LED products cost more than conventional lighting products, so end users assume they are already paying top dollar for quality.

- Warranties provide a level of trust and are a financial commitment from the manufacturer, but often require a level of commitment for maintenance. Poor maintenance voids the warranty.

- It's a hostile world: acid rain, extreme heat, sand storms, salt air - it's not realistic to expect things to last forever. However, we have to design and engineer products that will fit their environment. Water infiltration is a serious issue in outdoor lighting. IP (Ingress Protection) Ratings are needed for every luminaire used outdoors. A UL listing for wet locations is not adequate.

\section{Installing/Commissioning/Integrating}

- Could luminaire manufacturers certify an installation? The specifier could work with the manufacturer on an installation specification, and a $3^{\text {rd }}$ party commissioning agent could participate in the installation, evaluate whether the installation conforms with the design intent, create a training plan for maintenance, provide a user's manual, and check back in 6 months. All of this adds significant cost to a project.

- Need a commissioning protocol from manufacturers, to give specifiers and end users a way to estimate time and process and cost of commissioning.

\section{Product Performance}

- Specifiers and customers buying lighting need to be educated on statistics, what reliability means, what lifetime means, and what to expect from an LED product advertised with 50,000 hours life.

- Color shift in LED strips may necessitate a product changeout in 2 years, and it needs to be replaceable with a product with the same color, intensity, size, and connectors. Long-term color maintenance is a big issue. CQS is a more reliable color rendering scale than CRI, and we should encourage labs and manufacturers to report these values. Too many manufacturers are pushing high- 
CCT LEDs because of efficacy goals. Lower CCT and higher color quality may be an appropriate tradeoff for high efficacy for many applications.

- Most lighting markets are hung up on low cost, and manufacturers cut quality to meet that cost target. That gives LED products a poor reputation in the marketplace.

- For life safety reasons, some products will need a "kill mechanism" built in to extinguish the LED when its light output drops below a minimum level.

\section{Testing and standards}

- Long-term testing is needed on components. There is no data on how long things will last. LM-80 is especially a problem because there is no way to anticipate light output beyond 10,000 hours. And, at $10 \mathrm{~K}$ hours, the LED chip is obsolete.

- Ensuring LED luminaire compatibility with controls may require standardized protocols and component specifications.

- Standard wiring conventions (e.g., between LED and driver and power supply) will provide cues for installers and prevent them from reversing polarity, underloading or overloading the drivers, etc. Protective circuits built into drivers will prevent a lot of installation hassles and costly overnighting of replacement parts. When are parts interchangeable? How do you tell if the circuit is wired DC or AC?

- It would be helpful to have standardized tests for outdoor luminaires with heat sinks clogged by dirt, or where ambient temperatures are over $100^{\circ} \mathrm{F}$.

- Numerical standards are needed for flicker and dimming of LEDs.

- Controls are critical to a sustainable building. LED products must integrate with controls seamlessly. We need to develop standard connectors, standard wiring, and standard protocols for communication among components.

- Is it possible to have $3^{\text {rd }}$ party testing of different dimming products with LEDs for compatibility?

\section{Disposal/Recycling}

- If fixtures and/or their components will be obsolete by L70, manufacturers have to design disposable fixtures, designed for cradle-to-cradle recycling. Can the manufacturer implement a takeback policy? Place an 800 number for the facilities person to call, on a sticker on the luminaire (that won't fall off prematurely). Ship out the replacement luminaire and have the old fixture shipped back in the same box. The luminaire manufacturer is then responsible for recycling.

- More information is needed on toxicity, use of rare earth metals, and embodied energy of LED products and components. Would labeling of the embodied energy or CO2 emissions help users choose better products? 


\section{Where do we go from here?}

Jim Brodrick, Department of Energy

The DOE SSL Program is very responsive, listening to industry suggestions, testing new programs and directions.

Consequently, the DOE is always willing to hear about new approaches to improving SSL products and energy-efficient lighting adoption. Stay in touch. There will be an SSL Market Introduction Workshop in Philadelphia in July 2010 to continue the conversation.

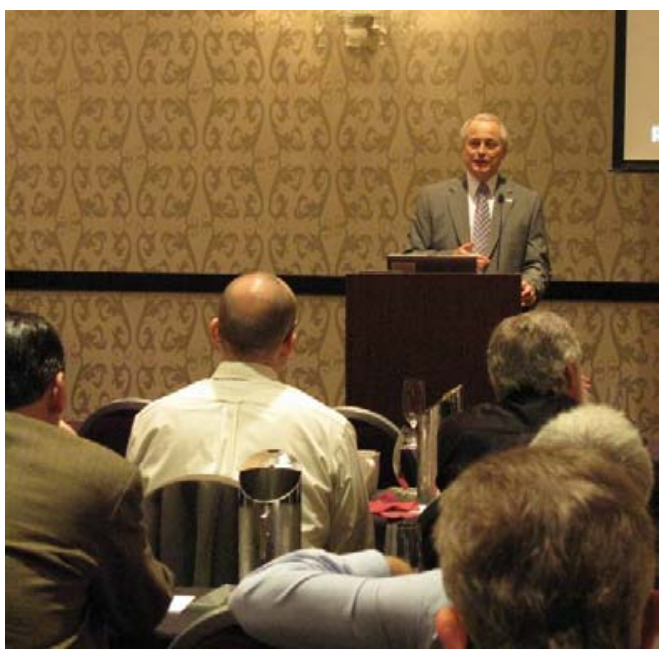

Figure 13. James Brodrick 

Appendix A

SSL in Higher Education Workshop Agenda 



\title{
Appendix A
}

\section{SSL in Higher Education Workshop Agenda}

\author{
SSL in Higher Education Workshop \\ Sponsored by the US Department of Energy \\ Tuesday May 25th, 2010 -Thursday May 27th, 2010 \\ The Nines Hotel, Portland, Oregon
}

\begin{tabular}{|c|l|l|}
\hline \multicolumn{3}{|c|}{ Tuesday May 25th, 2010 } \\
\hline Time & \multicolumn{1}{|c|}{ Topic } & \multicolumn{1}{c|}{ Speaker } \\
\hline $4.00 \mathrm{pm}-6 \mathrm{pm}$ & $\begin{array}{l}\text { Getting up to speed: LED experts talk about the } \\
\text { current technology, addressing color, light output, } \\
\text { life, temperature, power supplies and drivers, etc. } \\
\text { This will present the CALiPER testing program, } \\
\text { how it helps identify better LED products and } \\
\text { provides a snapshot of the LED industry. }\end{array}$ & $\begin{array}{l}\text { Pacific Northwest National Laboratory } \\
\text { (PNN) Staff }\end{array}$ \\
\hline
\end{tabular}

\begin{tabular}{|c|c|c|}
\hline \multicolumn{3}{|c|}{ Wednesday May 26th, 2010} \\
\hline Time & Topic & Speaker \\
\hline 8.00am-8.30am & $\begin{array}{l}\text { What are we doing here? } \\
\text { Welcome and Workshop Introduction }\end{array}$ & $\begin{array}{l}\text { Jim Brodrick, Department of Energy } \\
\text { Naomi Miller, PNNL }\end{array}$ \\
\hline $8.30 \mathrm{am}-9.15 \mathrm{am}$ & Lighting Design: the barriers to LED adoption & Jeff Miller, Pivotal Lighting Design \\
\hline $9.15 \mathrm{am}-10 \mathrm{am}$ & $\begin{array}{l}\text { Keeping Up Appearances...Designing, Building and } \\
\text { Maintaining attractive and effective spaces }\end{array}$ & Jean Stark, JMZ Architects \\
\hline $10.00 \mathrm{am}-10.30 \mathrm{am}$ & Open Discussions on Morning Topics & \\
\hline 10.30am-11.15am & Here are the Constraints: Manufacturing POV & Terry Clark, Finelite \\
\hline $11.15 \mathrm{am}-12 \mathrm{pm}$ & $\begin{array}{l}\text { Light and Systems: meeting rooms, classrooms, labs, } \\
\text { dining facilities }\end{array}$ & $\begin{array}{l}\text { Randy Burkett, RBLDI } \\
\text { Walter Kroner, Rensselaer }\end{array}$ \\
\hline $12 \mathrm{pm}-12: 30 \mathrm{pm}$ & Panel discussion and audience questions & Moderated Panel \\
\hline $12.30 \mathrm{pm}-1.30 \mathrm{pm}$ & Working Lunch Topic Tables & $\begin{array}{l}\text { All. Participants will sign up for a } \\
\text { topic during registration. Tables will } \\
\text { be labeled with a topic, and } \\
\text { participants will join that table for } \\
\text { lunch and discussion. }\end{array}$ \\
\hline $1.30 \mathrm{pm}-2.30 \mathrm{pm}$ & $\begin{array}{l}\text { What was everyone else talking about? } \\
\text { Summarizing all the Topic Tables }\end{array}$ & Panel \\
\hline $2.30 \mathrm{pm}-3.00 \mathrm{pm}$ & Open Discussions on Lunch Topics & \\
\hline $3.00 \mathrm{pm}-3: 45 \mathrm{pm}$ & $\begin{array}{l}\text { Light for Brains: Display and Task Lighting in } \\
\text { Libraries, Clinical Labs }\end{array}$ & $\begin{array}{l}\text { Chad Groshart, atelier ten } \\
\text { Christie Day, Yale Medical School }\end{array}$ \\
\hline $3.45 \mathrm{pm}-4: 15 \mathrm{pm}$ & Panel discussion and audience questions & Moderated Panel \\
\hline $4: 15 \mathrm{pm}-5: 00 \mathrm{pm}$ & $\begin{array}{l}\text { A Shot of Reality With a Chaser of Inspiration: } \\
\text { Theatres, Museums, Music Spaces, Historic } \\
\text { Buildings, Conference Centers }\end{array}$ & $\begin{array}{l}\text { Patty Glasow, Auerbach Glasow French } \\
\text { Ann Reo, io Lighting/Cooper Lighting }\end{array}$ \\
\hline $5.00 \mathrm{pm}-5.30 \mathrm{pm}$ & Panel discussion and audience questions & Moderated Panel \\
\hline $5.30 \mathrm{pm}-7 \mathrm{pm}$ & NGLIA's Opening Reception & Everyone's invited \\
\hline
\end{tabular}




\section{SSL in Higher Education Workshop}

Sponsored by the US Department of Energy

Tuesday May 25th, 2010-Thursday May 27th, 2010

The Nines Hotel, Portland, Oregon

\begin{tabular}{|l|l|l|}
\hline \multicolumn{2}{|c|}{ Thursday May 27th, 2010 } \\
\hline \multicolumn{1}{|c|}{ Time } & \multicolumn{1}{|c|}{ Topic } & \multicolumn{1}{|c|}{ Speaker } \\
\hline 8.00am-9.15am & $\begin{array}{l}\text { Light Outside: Campus Walkways, Roadways, } \\
\text { Parking Lots, Garages, Façade Lighting }\end{array}$ & $\begin{array}{l}\text { Sandra Stashik, Grenald Waldron Associates } \\
\text { William Evans, Princeton University }\end{array}$ \\
\hline 9.15am-10.15am & Panel discussion and audience questions & Moderated Panel \\
\hline 10.15am-10.45am & $\begin{array}{l}\text { What did we learn from all of this? } \\
\text { Synthesis: How to move forward addressing } \\
\text { these issues? What resources would be helpful? } \\
\text { What products are needed? How can we help } \\
\text { manufacturers provide products that meet these } \\
\text { needs? }\end{array}$ & $\begin{array}{l}\text { Naomi Miller, PNNL } \\
\text { Ku'uipo Curry, PNNL }\end{array}$ \\
\hline 10.45am-11am & $\begin{array}{l}\text { Where do we go from here? } \\
\text { Where to go for help when you need it, tools, } \\
\text { resources, support, alliances }\end{array}$ & Jim Brodrick, Department of Energy \\
\hline 11am-12pm & Q $A$ A & Naomi Miller, PNNL \\
\hline
\end{tabular}


Appendix B

\section{Attendee List}





\section{Appendix B}

\section{Attendee List}

Yaser Abdelsamed

Acuity Brands Lighting

Michael Arndt

Visa Lighting

Bill Bader

iNEMI

Curt Blaszczyk

SPI LIGHTING

Randy Borden

Borden Lighting

Jim Brodrick

U.S. Department of Energy

Randy Burkett

RBLDI

Ryan Carlson

Redwood Systems, Inc.

George Cederberg

Ceco Services

Michael Chan

Digital Lighting Inc.

Marc Chason

Marc Chason and Associates

Ron Church

Portland State University

Terry Clark

Finelite

Cason Coplin

EcoFit Lighting

Gary Corcoran

LED-ERA

Steve Crimi

Lumastream LLC

Ku'uipo Curry

PNNL

Ken Czech

Philips Lightolier

Christie Day
Yale Medical School

Cy Eaton

Philips

William Evans

Princeton University

Greg Frankiewicz

Energy Focus

Francisco Garza

Philips Sustainable Lighting

Patty Glasow

Auerbach Glasow French

Kelly Gordon

PNNL

Morris Green

Contract Hardware Engineering

Chad Groshart

Atelier 10

Doug Hagen

B-K Lighting + Teka Illumination

Tim Haley

Sylvania

Eric J. Haugaard

Ruud Lighting, Inc.

Tom Healy

ERCO Lighting, Inc.

Nathan Heiking

Kenall Lighting

BT Hwang

HEP USA

Mike Jackson

American De Rosa Lamparts

Sunset Lighting \& Fans

Jim Kahn

Aphos LIGHTING

Ken Kane

LSI, Inc.

Kandy Kernes
Lighting Science Group Corp

Bruce Kinzey

PNNL

Michael Kretsmer

Endicott Research Group

Chris Kreuter

Insight Lighting

Walter Kroner

Rensselaer Polytechnic Institute

Ron Lancial

Amerillum Brands

Jeff Lancial

Amerillum Brands

Marlowe Leafty

University of Maryland

Marc Ledbetter

PNNL

Mark Lien

Hubbell Lighting

Kunyueh (Steve) Lin

Delta Electronics Inc.

Bob Lingard

PNNL

Shannon Markey

Q-Tran, Inc.

Jeff McCullough

PNNL

Don McDaniel

Luminus Devices

Chad McSpadden

H.E. Williams

Patrick Miller

Opto-Electronix

Jeff Miller

Pivotal Lighting Design

Naomi Miller

PNNL 


\author{
Ralph Mosher \\ Sylvania \\ Kirsten Murray \\ Satco Products, Inc. \\ Muhinthan Murugesu \\ Osram Opto Semiconductors \\ Rob Nachtrieb \\ Lutron Electronics Co., Inc. \\ Al Near \\ USAI, LLC \\ Chris Nye \\ Leotek \\ Doug Oppedal \\ Energy Trust of Oregon \\ Betty Lou Pacey \\ $\mathrm{BL}$ Innovative Lighting \\ Michael Poplawski \\ PNNL \\ Chris Primous \\ Permlight \\ Ann Reo \\ io/Cooper Lighting
}

Michael Riebling

Philips Hadco

Larry Sadwick

InnoSys, Inc.

Linda Sandahl

PNNL

Tim Scharnagle

Sternberg Lighting

William Schrader

Philips--Sportlite, Inc.

Steve Silverstein

Kurt Versen Company

Chris Smit

US LED LTD

Greg Smith

Oregon State University

Greg Smith

Tivoli, LLC

Jean Stark

JMZ Architects

Sandra Stashik

Grenald Waldron
Heidi Steward

PNNL

Aijaz Taj

Lights of America

Jason Tuenge

PNNL

Dana Wallace

Philips-DayBrite

Rich Warmke

Lunera Lighting

Kevin Watkins

Washington University

Richard Westlake

Abundance Technologies

Jane White

Finelite, Inc.

Hirsohi Yagi

IMAnet, Inc.

Jeremy Yon

Litecontrol

John Yriberri

Xicato 



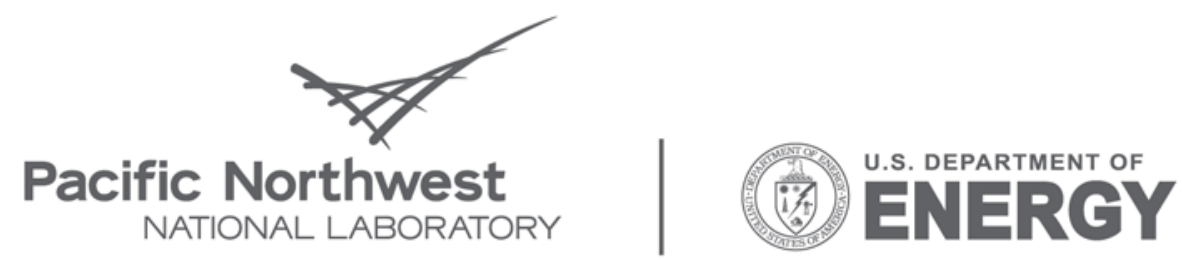

Proudly Operated by Battelle Since 1965

902 Battelle Boulevard

P.O. Box 999

Richland, WA 99352

1-888-375-PNNL (7665)

www.pnl.gov 